\title{
INVESTIGATION ON COMPRESSIVE FATIGUE DAMAGE PROCESS OF ULTRA- HIGH TOUGHNESS CEMENTITIOUS COMPOSITES
}

\author{
BOTAO HUANG*, QINGHUA LI*, SHILANG XU* AND BAOMIN ZHOU* \\ "Zhejiang University \\ Hangzhou, China \\ e-mail: botaohuang@zju.edu.cn, liqinghua@zju.edu.cn, slxu@zju.edu.cn, zbmzjg@zju.edu.cn
}

Key words: Ultra-high toughness cementitious composites; Compressive fatigue; Failure mode of fibers; Failure process

\begin{abstract}
Ultra-high toughness cementitious composites (UHTCC) is a kind of cementitious material reinforced by random distributed short fibers, which was proposed by Li and Leung and was designed with micromechanical principles to achieve the strain hardening behavior. This material has potential use in particular environments and structures that experience repeated or fatigue loads. Considering that the fatigue behavior of ultra-high toughness cementitious composites under compression is crucial for its application in certain conditions (e.g. airport runway and road pavements) and fatigue damage of structural components might be affected by both the flexural and compressive fatigue behaviors, the available work is rather limited and a better understanding of the compressive fatigue behavior is required. In this study, a series of monotonic and fatigue tests were performed to investigate the fatigue behavior of this material under compression. Compressive fatigue tests were conducted on 32 cylinder specimens $(70 \mathrm{~mm}$ in diameter and $140 \mathrm{~mm}$ in height). The loading frequency of fatigue tests was set as $4 \mathrm{~Hz}$ and the maximum stress was $90 \%, 85 \%, 80 \%, 75 \%, 70 \%$ and $65 \%$ of the compressive strength with the stress ratio (the ratio between the minimum fatigue loads to the maximum fatigue load) set constant as 0.1 . The $S-N$ relationship of ultra-high toughness cementitious composites was given, which indicates that the fatigue life of this material is higher than that of plain concrete and steel fiber reinforced concrete under the same stress level. It is observed that, the specimen failure mode of ultra-high toughness cementitious composites is similar to that of strain softening fiber reinforced concrete. The failure surface and damage process of this material were investigated. A new failure mode of PVA fiber with crush end was discovered with the help of SEM analysis and EDS analysis. This failure mode forms by the ruptured end of fibers experiencing repeated crushing and friction. Besides, based on the various failure modes of PVA fibers, the fatigue failure surface could be divided into three regions, including fatigue source region, transition region and crack extension region. During fatigue failure process, micro cracks initiate in the fatigue source region, propagate in the transition region and form main crack in the crack extension region.
\end{abstract}

\section{INTRODUCTION}

Fiber reinforced concrete is made by adding fibers into the concrete matrix to improve its ductility. With fiber reinforced concrete widely applied in modern complicated structures, which subject to repetitive cyclic loads (e.g. automobile traffic, wind action and sea waves), the fatigue behavior of this material is also getting more and more attention. Numerous experiments have been conducted to study the fatigue behavior of fiber reinforced concrete [18]. Ultra-high toughness cementitious composites (UHTCC) [9] is a kind of cementitious material reinforced by random 
distributed short fibers, which is also referred to as engineered cementitious composites (ECC) [10], strain hardening cementitious composites (SHCC) [11], polyvinyl alcohol (PVA) fiber reinforced cementitious composites (PVAFRCC) [12], and its use has been explored throughout the world. It was proposed by $\mathrm{Li}$ and Leung and was designed with micromechanical principles to achieve the strain hardening behavior [13]. This material has potential use in complicated environments and structures that are subjected to repeated or fatigue loads, such as airport runway, highway pavements, bridge decks and offshore platform, due to its high ductility [9, 14-16] and durability [17-20]. To apply ultra-high toughness cementitious composites in practice, the investigation of fatigue behavior of this material is needed.

Several studies have been carried out focusing on fatigue behavior of UHTCC in the past decade. Fatigue failure characteristics and fiber bridging characteristics of UHTCC under flexure were investigated and it was found that UHTCC exhibited significantly higher fatigue life and more ductility than concrete, polymer cement mortar and steel fiber reinforced concrete [21-25]. In addition, flexural fatigue behavior of concrete beams with UHTCC layer [26-28] and the tensile failure property of UHTCC under monotonic and cyclic tensile loads $[29,30]$ has been studied. Up to now, the existing study is mainly focused on the behavior of UHTCC under flexural fatigue and cyclic tensile loads, while there is limited study on the compressive fatigue properties of UHTCC. Considering that the fatigue behavior of UHTCC under compression is crucial for its application in certain conditions (e.g. airport runway and road pavements) and fatigue damage of structural components are affected by both the flexural and compressive cyclic loading, the available work is rather limited and a better understanding of the compressive fatigue behavior is required.

Thus, in order to investigate the fatigue behavior of UHTCC under compression, a series of monotonic and fatigue tests were performed. This paper focuses on the evaluation of failure process of UHTCC, including fatigue life and failure mode of fibers on the failure plane. Emphasis will be placed on analysis of the damage process of this material under fatigue loads. Finally, relevant conclusion are draw, which could be used as a reference for a wider application of UHTCC in structures.

\section{EXPERIMENTAL PROGRAM}

\subsection{Specimen preparation}

In this experiment, UHTCC was produced using cementitious binders, fine silica sand, water, superplasticizer and PVA fiber [9]. The binders were composed of ordinary Portland cement and fly ash. The PVA fiber was KURALON K-II REC15 type with corresponding properties given in Table 1 and fibers added to the mix were $2 \%$ of the total composite volume. Two series of UHTCC cylinder specimens (Series I \& II) with the same mix were prepared, the dimensions of which were $70 \mathrm{~mm}$ (diameter) $\times 140 \mathrm{~mm}$ (height). The specimens were demolded $72 \mathrm{~h}$ after they were cast and were cured for 28 days. Then, the specimens were laid in common environment (around $15{ }^{\circ} \mathrm{C}$ and the relative humidity between $30 \%$ and $50 \%$ ) for 3 months before monotonic and fatigue test.

Table 1: Properties of PVA fiber

\begin{tabular}{ccccc}
\hline $\begin{array}{c}\text { Tensile } \\
\text { strength } \\
(\mathrm{MPa})\end{array}$ & $\begin{array}{c}\text { Diame- } \\
\text { ter } \\
(\mu \mathrm{m})\end{array}$ & $\begin{array}{c}\text { Fiber } \\
\text { length } \\
(\mathrm{mm})\end{array}$ & $\begin{array}{c}\text { Young's } \\
\text { modulus } \\
(\mathrm{GPa})\end{array}$ & $\begin{array}{c}\text { Elong- } \\
\text { ation } \\
(\%)\end{array}$ \\
\hline 1600 & 40 & 12 & 40 & 6 \\
\hline
\end{tabular}

\subsection{Testing Method}

The compressive and fatigue test were performed in a $1000 \mathrm{kN}$ INSTRON testing system. The displacement between platens was measured. For monotonic tests, displacement control was adopted with a constant rate of 0.20 $\mathrm{mm} / \mathrm{min}$. The average static compressive strength of Series I was 43.08 MPa (6 specimens), while that of Series II was 38.22MPa (10 specimens). For fatigue test, a constant amplitude fatigue load was used. The tests were carried out under load control with a sinusoidal waveform of $4 \mathrm{~Hz}$. Six different stress levels were considered. Those maximum 
stress levels were $0.90,0.85,0.80,0.75,0.70$ and 0.65 , respectively, of the static compressive strength of UHTCC, shown in Table 2. Note that the specimen of Series I was used in the fatigue tests under the stress level of $0.90,0.80$, 0.70 and 0.65 and Series II was used in the remainder of the test. The ratio between the minimum fatigue loads to the maximum fatigue load $\left(R=P_{\min } / P_{\max }\right)$ was constant at 0.1 . The fatigue test commenced with a ramp to the maximum load at a rate of $8 \mathrm{kN} / \mathrm{s}$ followed by a sine waveform fatigue loading.

Table 2: Fatigue load and specimen numbers of the test

\begin{tabular}{ccccc}
\hline $\begin{array}{c}\text { Stress } \\
\text { levels }\end{array}$ & Series & $\begin{array}{c}\text { Static } \\
\text { compressive } \\
\text { strength } \\
\text { (MPa) }\end{array}$ & $\begin{array}{c}\text { maximum } \\
\text { fatigue } \\
\text { load } \\
\text { (MPa) }\end{array}$ & $\begin{array}{c}\text { Specimen } \\
\text { numbers }\end{array}$ \\
\hline 0.90 & I & 43.08 & 38.76 & 6 \\
0.85 & II & 38.22 & 32.50 & 6 \\
0.80 & I & 43.08 & 34.47 & 6 \\
0.75 & II & 38.22 & 28.68 & 6 \\
0.70 & I & 43.08 & 30.16 & 6 \\
0.65 & I & 43.08 & 28.00 & 2 \\
\hline
\end{tabular}

After specimen failure, the crushed pieces on the failure surface of specimens were selected for scanning electronic microscope (SEM) tests and Energy-dispersive X-ray spectroscopy (EDS) was utilized for the elemental analysis, as well as point analysis from the sample surface.

\section{RESULTS AND DISCUSSION}

\subsection{Fatigue life}

The fatigue lives for each fatigue stress level are summarized in Table 3, which were obtained from the above experiment study. Note that fatigue test was ended when load cycles reached two million and fatigue failure of the specimen did not happen.

Table 3: Test result for fatigue life of UHTCC at various stress levels

\begin{tabular}{ccccccc}
\hline \multirow{2}{*}{ No. } & \multicolumn{7}{c}{ Stress levels } \\
\cline { 2 - 7 } & 0.90 & 0.85 & 0.80 & 0.75 & 0.70 & 0.65 \\
\hline 1 & 620 & 1500 & 9520 & 42524 & 484135 & $2000000^{*}$ \\
2 & 700 & 1869 & 28394 & 149691 & 679756 & $2000000^{*}$ \\
3 & 1100 & 1928 & 35908 & 497273 & 1054123 & $/$ \\
4 & 1572 & 4052 & 55629 & 718343 & 1906379 & $/$ \\
5 & 1586 & 4115 & 108081 & 792262 & $2000000^{*}$ & $/$ \\
6 & 1900 & 13019 & 131442 & 1295229 & $/$ & $/$ \\
\hline
\end{tabular}

Note: * represents the fatigue failure did not happen when load cycles reached two million.
The number of cycles to failure on fatigue test follows Weibull distribution. The test data and fatigue equations are plotted in Fig. 1 and the arrow in this figure indicates that the fatigue failure did not happen when load cycles reached two million.

Table 4: Fatigue equations of UHTCC, plain concrete and SFRC

\begin{tabular}{cc}
\hline Materials & Fatigue equation \\
\hline UHTCC & $S=-0.0618 \log N+1.0837$ \\
Plain & \\
concrete of & $S=-0.0617 \log N+1.0000$ \\
Eq. (1) [31] & \\
SFRC $(0.5$ & $S=-0.0632 \log N+0.9987$ \\
Vol \%) [6] & \\
SFRC $(1.0$ & $S=-0.0497 \log N+0.9697$ \\
Vol \%) [6] & \\
\hline
\end{tabular}

Note: Vol \% means the percentage of steel fibers by volume of concrete.

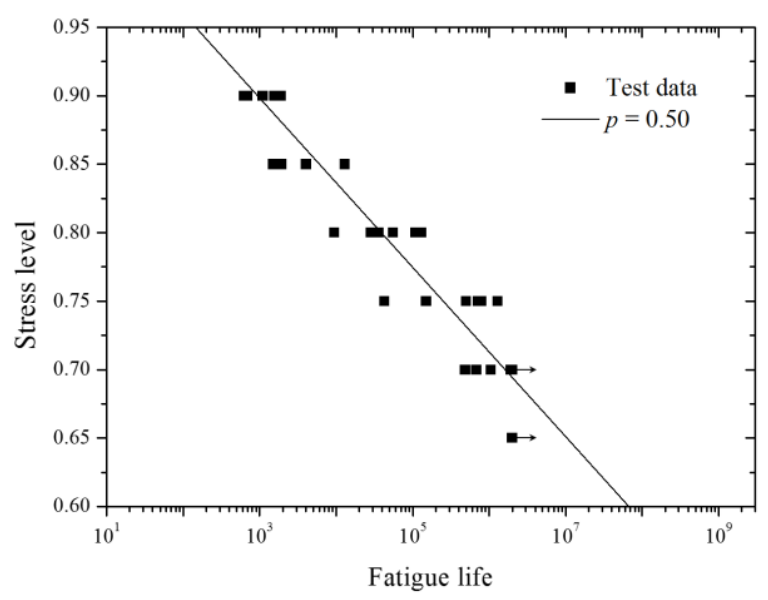

Figure 1: Experimental fatigue life and fatigue curves of UHTCC.

For the sake of comparison, several fatigue equations of plain concrete and steel fiber reinforced concrete (SFRC) are shown in Table 4. For plain concrete, the classical $S-N$ fatigue equation [31] is as follows:

$$
\sigma_{\max } / f_{\mathrm{c}}=1-(1-R) \beta \log N
$$

Where $\sigma_{\max }$ is the maximum stress in fatigue test; $f_{\mathrm{c}}$ is the static compressive strength; $\beta$ is a material parameter, it equals 0.0685 ; and $R$ equals 0.1 . For steel fiber reinforced concrete (SFRC), the equations in [6] are used. Note that, the single-logarithm fatigue equations in [6] , 
which is an overview article, came from the test data published in [2] [3] [4] [32]. In Fig. 2, the $S$ - $N$ curves of UHTCC, plain concrete and steel fiber reinforced concrete are plotted. It should be noted that the curve of UHTCC is from the single-logarithm fatigue equation when failure probability is 0.50 .

Although there are numerous combinations which can influence the fatigue behavior of plain concrete and steel fiber reinforced concrete, due to the numerous sources of fatigue data analyzed, the qualitative trends observed should be generally applicable [6] Hence, it could be seen that the fatigue life of UHTCC is higher than that of plain concrete and steel fiber reinforced concrete under the same stress level.

This phenomenon might be related to the relatively higher fiber percentage of fibers by volume ( $2 \mathrm{Vol} \%)$ of UHTCC, due to the fact that the fibers can bridge cracks thus contribute to substantially enhance the postpeak behavior in compression [16]. That is to say, a possible explanation is that UHTCC owns higher toughness and ductility compared with plain concrete and steel fiber reinforced concrete. Also, further experimental work and study are required to understand the mechanism of this phenomenon.

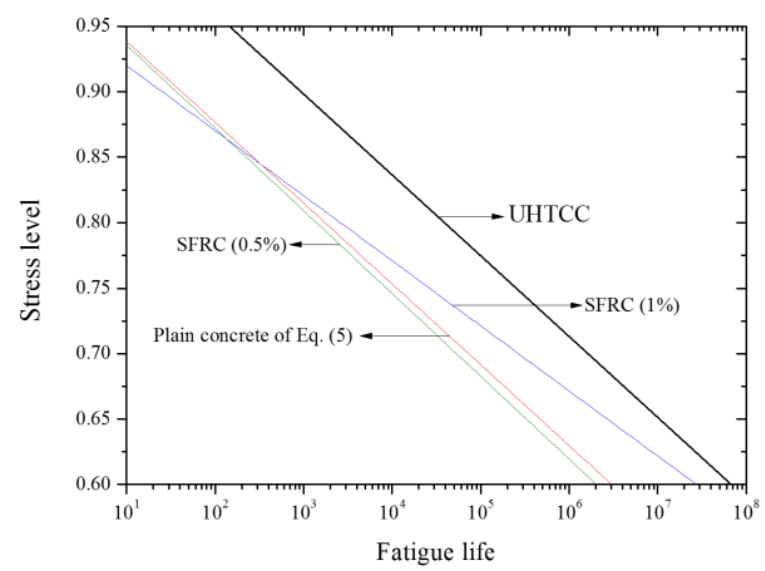

Figure 2: $S$ - $N$ curves of UHTCC, plain concrete and steel fiber reinforced concrete under compression fatigue load

\subsection{Fatigue damage mechanism}

\subsubsection{Fatigue failure mode}

Typical fatigue failure modes of UHTCC specimens under compression are shown in Fig. 3 . It can be seen that major inclined shear cracks formed along the specimens with the cracking plane approximately $60-90^{\circ}$ from the horizontal plane and the specimen did not burst into pieces after failure, which is different from that of concrete and similar to steel fiber reinforced concrete [33]. The static and fatigue failure modes of UHTCC are close and it could be attributed to the bridging interaction between PVA fibers and the cementitious matrix, which kept the specimens in integrity after failure.

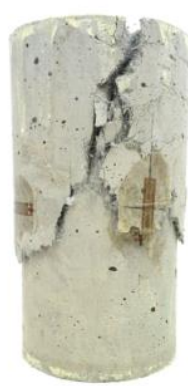

(a)

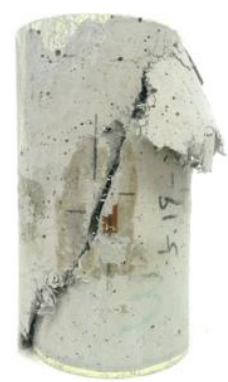

(b)

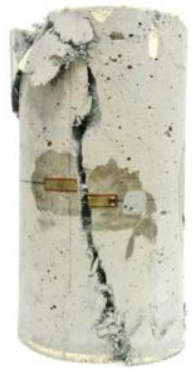

(c)
Figure 3: Typical fatigue failure modes of cylindrical specimens under compression

\subsubsection{Fatigue failure surface}

To investigate the damage process of UHTCC, the failure surfaces of the specimen under fatigue load are shown in Fig. 4.

For the fatigue failure surface, three regions could be divided by macroscopic observation. As shown in Fig. 4, there exists relatively "flat" areas named Region $\mathrm{A}_{\mathrm{f}}$ surrounded by dashed line. Also, PVA fibers could not be practically observed by naked eye. In addition, a relatively "rough" area with numerous PVA fibers observed by the naked eye named Region $\mathrm{B}_{\mathrm{f}}$. The emphasis on fatigue failure surface should be the area called $C_{f}$, which is surrounded by solid line in Region $A_{f}$. Different from Region $\mathrm{A}_{\mathrm{f}}$ and Region $\mathrm{A}_{\mathrm{s}}$, this area is much "darker" compared to surrounding areas by macroscopic observation and there exists a trace of "friction".

Note that the region division by macroscopic observation was qualitative and typical, but rather rough, which would be used to analyze and get deeper understanding of the damage process in the following part, and there also 
might be some parts of the failure surface with above features not being marked in the figure.

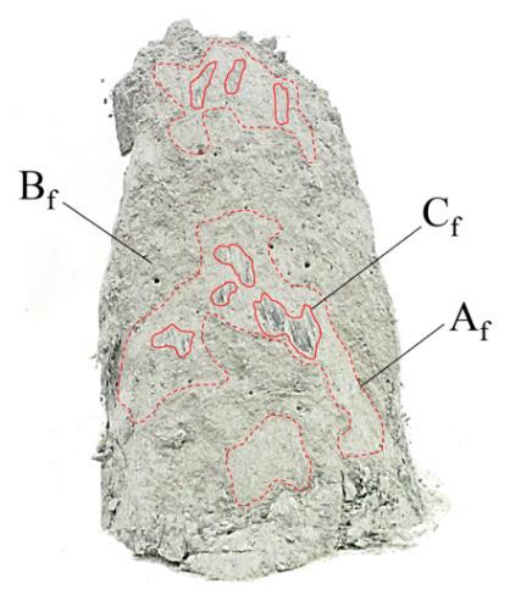

Figure 4: Fatigue failure surface of UHTCC specimens

\subsubsection{SEM analysis}

Scanning electron microscopy (SEM) was performed in order to study the behavior of PVA fibers on various regions of the fatigue failure surface. Fig. 5 illustrates the initial shape of a single PVA fiber, which could be used as a reference in the following analysis, and the SEM images of regions on failure surface are shown in Fig. 6, Fig. 7 and Fig. 8.

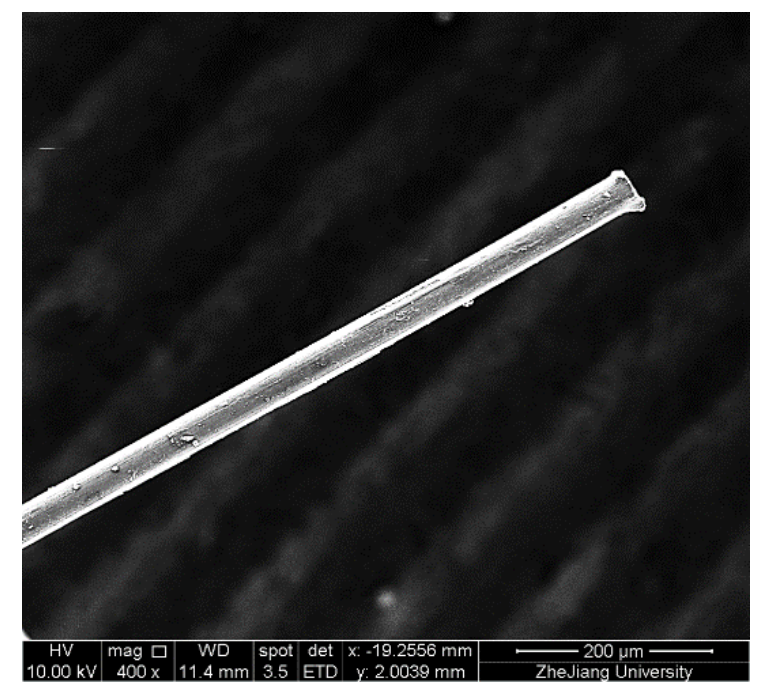

Figure 5: SEM image of PVA fiber

For fatigue failure surface, which has been divided into three regions, the SEM images are shown in Fig. 6 (Region $C_{f}$ ), Fig. 7 (Region $A_{f}$ ) and Fig. 8 (Region $\mathrm{B}_{\mathrm{f}}$ ). The emphasis would be placed on Region $\mathrm{C}_{\mathrm{f}}$, which is "darker" in macroscopic observation. In this region, a new damage mode of fibers, which seems like that the fibers suffered from crush and totally differs from that of ruptured or pull-out fiber end in Ref. [34], is shown. In Fig. 6, to confirm Mark 1 are PVA fibers, Energy-dispersive X-ray spectroscopy (EDS) is utilized for the preliminary analysis and the results are shown in Fig. 9, which indicates they are PVA fibers due to the relative high concentration of Carbon. Moreover, it should be noted that, in Region $\mathrm{C}_{\mathrm{f}}$, there exists clear trace of "friction", which has been illustrated above, and this trace of "friction" could also be found in SEM images which have been marked. It seems that the new damage shape of fibers might be related to the trace of "friction". A possible explanation for the form of new damage mode of fibers might be that the damaged fibers were ruptured in the early stage of fatigue failure process and the ruptured end suffered from repeated friction or crushing during the rest fatigue life. In the following part, this fiber end damage type can be named crush end. There are two damage modes in Region $\mathrm{A}_{\mathrm{f}}$ shown in Fig. 7. Part of the fibers were ruptured (e.g. Fiber 2), while the others were crushed (e.g. Fiber 3). Owing to most fibers were ruptured or crushed (lying very close to failure surface), Region $\mathrm{C}_{\mathrm{f}}$ and Region $\mathrm{A}_{\mathrm{f}}$ would be relative "flat" in macroscopic observation. But the reason why Region $\mathrm{C}_{\mathrm{f}}$ is "darker" is still unclear and it might be a result of friction or crushing. Further investigation is needed to explain this phenomenon. Finally, for Region $B_{f}$ shown in Fig. 8, the fibers with pull-out end (e.g. Fiber 4) existed with relatively high proportion, while the fibers with ruptured end (e.g. Fiber 5) existed with low proportion. Further discussion of fatigue failure surface and damage process will be given in the following section. 


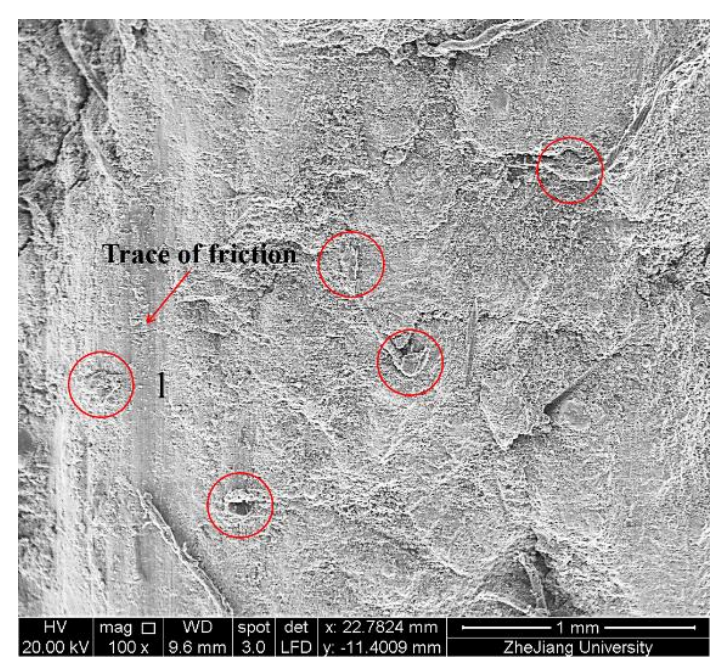

Figure 6: SEM image of "flat \& darker" area on fatigue failure surface (Region $\mathrm{C}_{\mathrm{f}}$ )

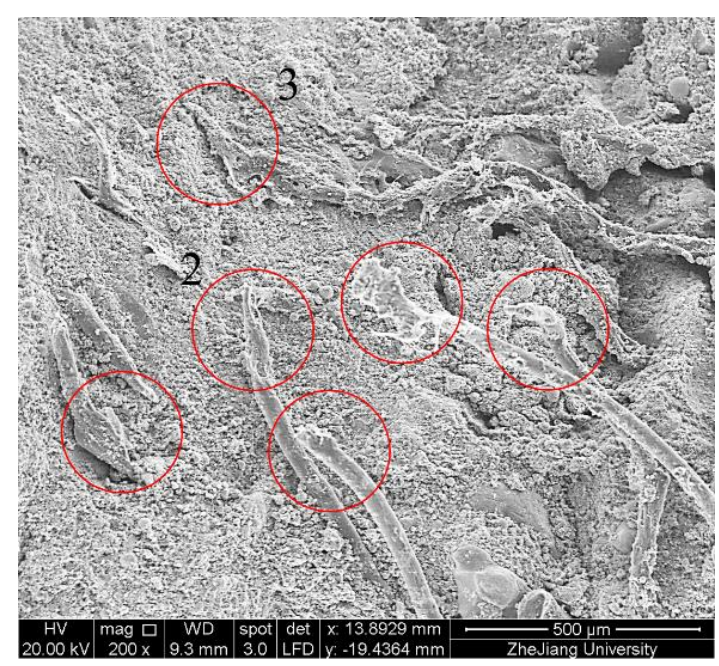

Figure 7: SEM image of "flat" area on fatigue failure surface (Region $\mathrm{A}_{\mathrm{f}}$ )

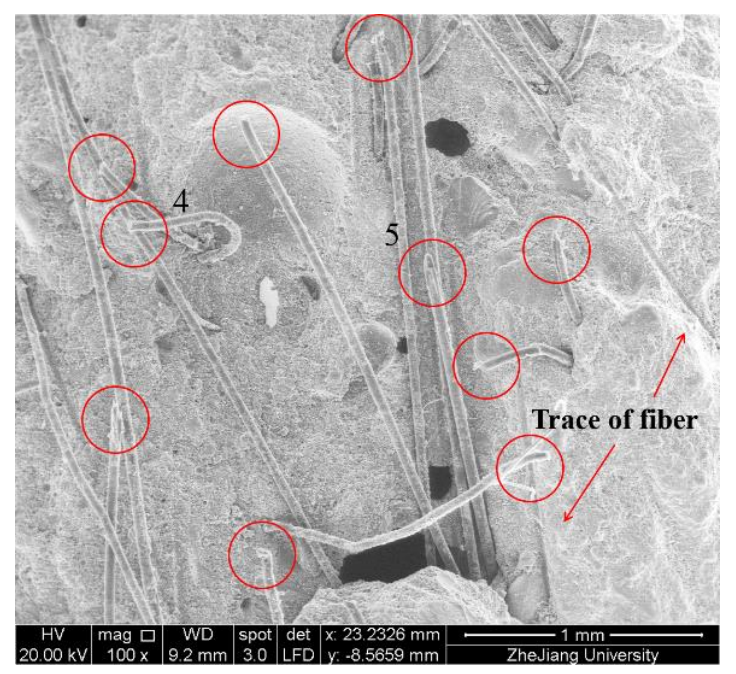

Figure 8: SEM image of "rough" area on fatigue failure surface (Region $\mathrm{B}_{\mathrm{f}}$ )

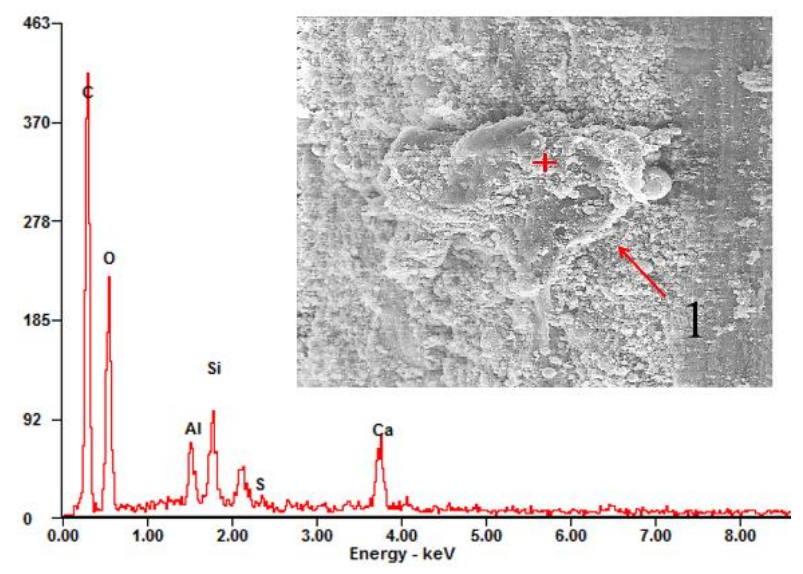

Figure 9: EDS analysis of the marked points

\subsubsection{Discussion of fatigue damage process}

Based on the above region division of the fatigue failure surface and the results of SEM analysis, damage processes in UHTCC under cyclic loading are illuminated .

In the early stage of fatigue damage, the micro cracks appear and propagate relative slowly and deformation of the specimen is relatively small,. Also, the fibers bridging cracks would mainly be ruptured in this stage. Then, the ruptured end of fibers in formed cracks would suffer repeated crushing and friction from the mix due to external fatigue load. This process distinguishes the fiber failure mode of fatigue damage from that in Ref. [34] and is the reason why the fibers seems to be crushed and the trace of friction could be found in Region $\mathrm{C}_{\mathrm{f}}$. Looking back to the above process, the micro cracks could be regarded as fatigue source. In other words, Region $\mathrm{C}_{\mathrm{f}}$ could also be regarded as the fatigue source, which can be discerned by macroscopic observation.

Meanwhile, the cracks continuously propagate until fatigue failure occurs. In this process, the cracks propagate from Region $C_{f}$ to Region $\mathrm{B}_{\mathrm{f}}$. It should be noted that there exists Region $\mathrm{A}_{\mathrm{f}}$ in fatigue damage process. Remember that the fibers in Region $A_{f}$ are mainly the fibers with crushed end or ruptured end, while the fibers in Region $B_{f}$ are the fibers with pull-out end and ruptured end. Thus, Region $\mathrm{B}_{\mathrm{f}}$ could be regarded as the area formed in later period that the deformation of specimen increases leading to the appearance of pull-out damaged fibers. Meanwhile, Region $A_{f}$ can be 
regarded as a transition area between Region $C_{f}$ and Region $\mathrm{B}_{\mathrm{f}}$. In summary, micro cracks initiate in fatigue source region, propagate in transition region and form main crack in extension region.

Regarding that the discussion of the damage process is based on qualitative analysis of failure surface and SEM analysis, further evidence and investigation, as well as quantitative analysis, are essential. In addition, a more accurate method to distinguish the crack-initiating regions (Region $\mathrm{C}_{\mathrm{f}}$ ) is needed due to macroscopic observation in this paper is a rather rough way. Also, the relationship between fatigue deformation and the degree of crack propagation should be paid more attention in further study.

\section{CONCLUSIONS}

A series of monotonic and fatigue tests were performed in this study to investigate the fatigue behavior of ultra-high toughness cementitious composites under compression. The $S-N$ relationship of UHTCC was given, which indicates that the fatigue life of this material is higher than that of plain concrete and steel fiber reinforced concrete under the same stress level. The failure surface and damage process of UHTCC were investigated. A new failure mode of PVA fiber with crush end was discovered with the help of SEM analysis and EDS analysis. This failure mode forms by the ruptured ends of fibers experiencing repeated crushing. The fatigue failure surface could be divided into three regions, including fatigue source region, transition region and crack extension region. During fatigue failure process, micro cracks initiate in fatigue source region, propagate in transition region and form main crack in crack extension region.

\section{ACKNOWLEDGEMENT}

The authors would like to acknowledge the financial supports provided by National Natural Science Foundation of China with grant No. 51378462 and 51008270.

\section{REFERENCE}

[1] Otter, D. E., and Naaman, A. E. 1988. Properties of steel fiber reinforced concrete under cyclic loading. ACI Materials Journal, 85(4): 254-261.

[2] Grzybowski, and M., Meyer, C. 1993. Damage accumulation in concrete with and without fiber reinforcement. ACI Materials Journal, 90: 594604.

[3] Paskova, T., and Meyer, C. 1997. Low-cycle fatigue of plain and fiber reinforced concrete. ACI Materials Journal, 94: 273-85.

[4] Cachim, P. B. 1999. Experimental and numerical analysis of the behaviour of structural concrete under fatigue loading with applications to concrete pavements. $\mathrm{PhD}$ thesis. Faculty of Engineering of the University of Porto, pp. 246.

[5] Cachim, P. B., Figueiras, J. A., and Pereira, P. A. A. 2002. Fatigue behavior of fiber-reinforced concrete in compression. Cement and Concrete Composites, 24(2): 211-217.

[6] Lee, M. K., and Barr, B. I. G. 2004. An overview of the fatigue behaviour of plain and fibre reinforced concrete. Cement and Concrete Composites, 26(4): 299-305.

[7] Saucedo, L., Yu, R. C., Medeiros, A., Zhang, X., and Ruiz, G. 2013. A probabilistic fatigue model based on the initial distribution to consider frequency effect in plain and fiber reinforced concrete. International Journal of Fatigue, 48: 308-318.

[8] Medeiros, A., Zhang, X. X., Ruiz, G., Yu, R. C., and Velasco, M. D. S. L. 2015. Effect of the loading frequency on the compressive fatigue behavior of plain and fiber reinforced concrete. International Journal of Fatigue, 70: 342-350.

[9] Li, H., Xu, S., and Leung, C. K. Y. 2009. Tensile and flexural properties of ultra high toughness cementitious composite. Journal of Wuhan University of Technology-Mater. Sci. Ed., 24(4): 677-683.

[10] Li, V. C. 1993. From micromechanics to structural engineering-the design of cementitious composites for civil engineering applications. Journal of Structural Mechanics \& Earthquake Engineering, 10(2): 37-48.

[11] Li, V. C., and Hashida T. 1993. Engineering ductile fracture in brittle-matrix composites. Journal of Materials Science Letters, 12(12): 898-901.

[12] Nelson, P. K., Li, V. C., Kamada, T. 2002. Fracture toughness of microfiber reinforced cement composites. Journal of Materials in Civil Engineering, 14(5): 384-391.

[13] Li, V. C., and Leung, C. K. Y. 1992. Steady state and multiple cracking of Short random fiber composites. Journal of Engineering Mechanics, 188(11), 2246-2264.

[14] Li, Victor C., S., Wang, and C., Wu. 2001. Tensile strain-hardening behavior of polyvinyl 
alcohol engineered cementitious composite (PVA-ECC). ACI Materials Journal, 98(6): 483492.

[15] Zhou, J., Pan, J., and Leung, C. 2015. Mechanical Behavior of Fiber-Reinforced Engineered Cementitious Composites in Uniaxial Compression. Journal of Materials in Civil Engineering, 27(1): 04014111.

[16] Xu, S. L., and Cai, X. R. 2010: Experimental study and theoretical models on compressive properties of ultrahigh toughness cementitious composites. Journal of Materials in Civil Engineering, 22(10): 1067-1077.

[17] Lepech, M. D., and Li, V. C. 2006. Long term durability performance of engineered cementitious composites. Restoration of Buildings and Monuments, 12(2), 119-132.

[18] Sahmaran, M., and Li, V. C. 2008. Durability of Mechanically Loaded Engineered Cementitious Composites under Highly Alkaline Environment. Cement and Concrete Composites, 30(2): 72-81.

[19] Sahmaran, M., Lachemi, M., and Li, V. C. 2009. Assessing the durability of engineered cementitious composites under freezing and thawing cycles. Journal of ASTM International, 6(7): 1-13.

[20] Xu, S., and Cai, X. 2010. Mechanics behavior of ultra high toughness cementitious composites after freezing and thawing. Journal of Wuhan University of Technology-Mater. Sci. Ed., 25(3), 509-514.

[21] Suthiwarapirak, P., Matsumoto, T., and Kanda, T. 2002. Flexural fatigue failure characteristics of an engineered cementitious composites and polymer cement mortars. Journal of Materials, Concrete Structures and Pavements, 57: 121-134.

[22] Matsumoto, T., Suthiwarapirak, P., and Kanda, T. 2003. Mechanisms of multiple cracking and fracture of DFRCC under fatigue flexure. Journal of advanced concrete technology, 1(3): 299-306.

[23] Suthiwarapirak, P., and Matsumoto, T. 2003. Fiber bridging degradation based fatigue analysis of ECC under flexure. Journal of applied mechanics, JSCE, 6: 1179-1188.

[24] Suthiwarapirak, P., Matsumoto, T., and Kanda, T. 2004. Multiple cracking and fiber bridging characteristics of engineered cementitious composites under fatigue flexure. Journal of Materials in Civil Engineering, 16(5): 433-443.

[25] Liu, W., Xu, S., and Li, Q. 2012. Study on flexural fatigue life of ultra-high toughness cementitious composites under constant amplitude cyclic loading. Journal of Building Structure, 33(1): 119-127. (in Chinese)

[26] Zhang, J., and Li, V. C. 2002. Monotonic and fatigue performance in bending of fiberreinforced engineered cementitious composite in overlay system. Cement and Concrete Research, 32(3): 415-423.

[27] Leung, C. K. Y., Cheung, Y. N., and Zhang, J. 2007. Fatigue enhancement of concrete beam with ECC layer. Cement and Concrete Research, 37(5): 743-750.

[28] Liu, W., Xu, S., and Li, Q. 2013. Flexural behaviour of UHTCC - layered concrete composite beam subjected to static and fatigue loads. Fatigue Fract. Fatigue \& Fracture of Engineering Materials \& Structures, 36(8): 738749.

[29] Jun, P., and Mechtcherine, V. 2010. Behaviour of strain-hardening cement-based composites (SHCC) under monotonic and cyclic tensile loading: part 1 - Experimental investigations. Cement and Concrete Composites, 32(10): 801809.

[30] Jun, P., and Mechtcherine, V. 2010. Behaviour of strain-hardening cement-based composites (SHCC) under monotonic and cyclic tensile loading: part 2: modeling. Cement and Concrete Composites, 32(10): 810-818.

[31] Aas-Jakobsen K. 1970. Fatigue of concrete beams and columns. In: University of Trondheim. Norwegian Institute of Technology. Division of concrete structures. Bulletin No. 70.

[32] Do, M. T., and Chaallal Aïtcin, P. C. 1993. Fatigue behavior of high performance concrete. Journal of Materials in Civil Engineering, 5: 96111.

[33] Song, Y. 2012. Dynamic Constitutive Relation and Failure Criterion of Concrete 1. Beijing: Science Press, pp.2-3, 114-116. (in Chinese)

[34] Redon, C., Li, V. C., Wu, C., Hoshiro, H., Saito, T., and Ogawa, A. 2001. Measuring and modifying interface properties of PVA fibers in ECC matrix. Journal of Materials in Civil Engineering, 13(6): 399-406. 